\title{
Identification of RAS genotypes that modulate blood pressure change by outdoor temperature
}

\author{
Yun-Chul Hong ${ }^{1,2}$, Ho Kim ${ }^{3}$, Youn-Hee Lim ${ }^{4}$, Hyung-Jin Yoon ${ }^{5,6}$, Young-Min Kwon ${ }^{7}$ and Minseon Park ${ }^{8}$ \\ The aim of this study was to evaluate the role of polymorphisms of renin-angiotensin system (RAS) genes in modulating \\ outdoor temperature-related blood pressure (BP) responses. Data for RAS gene polymorphisms, BP and outdoor temperature \\ were collected from 4903 subjects from February 2003 to August 2004. Generalized additive and linear models were \\ used to determine whether genetic variants of RAS affected the interplay between outdoor temperature and BP. Outdoor \\ temperature $\left({ }^{\circ} \mathrm{C}\right)$ was inversely associated with systolic BP and diastolic BP. These inverse relationships were stronger \\ in subjects with $A C E D D, A G T T T$ and AGTR1 AA genotypes. In contrast, significant positive temperature-dependent \\ $\mathrm{BP}$ responses were found at temperatures above $21.4^{\circ} \mathrm{C}$ in subjects with the AGTR1 $\mathrm{C}$ allele, but not at temperatures \\ below $21.4^{\circ}$. Our findings suggest that subjects with ACE DD, AGT TT or AGTR1 AA genotypes are susceptible to cold \\ temperature-induced BP increase, whereas subjects with AGTR1 $C$ allele have a high risk of BP elevation when exposed \\ to hot temperatures. \\ Hypertension Research (2013) 36, 540-545; doi:10.1038/hr.2012.218; published online 7 February 2013
}

Keywords: blood pressure; climate change; genetic polymorphism; renin-angiotensin system; temperature

\section{INTRODUCTION}

Temperature-related variation in blood pressure (BP) is an important risk factor for increased cardiovascular events in extreme weather. ${ }^{1}$ This relationship has been well documented in normal, ${ }^{2}$ hypertensive ${ }^{3}$ and elderly patients, ${ }^{4}$ as well as in patients with end-stage renal disease. ${ }^{5}$ As the environmental temperature changes, blood vessels can either dilate or constrict, thereby causing a dissipation or conservation of heat in the body. These changes in peripheral vascular resistance also result in variations in $\mathrm{BP}^{6}$ However, the relationship between environmental temperature and $\mathrm{BP}$ is complicated, and the mechanisms involved remain unclear. Considering genes involved in $\mathrm{BP}$ regulation, differences in genotype may contribute to variations in vascular responses to temperature.

The renin-angiotensin system (RAS) contributes to the regulation of BP by maintaining vascular tone and water-to-sodium balance. ${ }^{7}$ Accordingly, these genes may have an important role in regulating the effects of temperature on BP. Genetic variants of RAS, such as the angiotensin-converting enzyme (ACE) insertion/deletion (I/D), angiotensinogen (AGT) M235T and angiotensin II type 1 receptor (AGTR1) A1166C polymorphisms have been implicated in the progression of hypertension. ${ }^{8,9}$ In addition, these variants contribute to the development of coronary heart disease. ${ }^{10-12}$
The ACE is a primary component of RAS. This protein is widely accepted as being involved in the regulation of BP and sodium homeostasis. The levels of ACE activity in plasma and tissues are regulated, at least in part, by genetic polymorphisms. These polymorphisms include either the presence (insertion $(I)$ ) or absence (deletion $(D)$ ) of a 287-base-pair element in intron $16 .{ }^{8,11}$ Subjects carrying the ACE $D$ allele have increased ACE serum activity. ${ }^{8}$ On the other hand, the presence of the AGT $235 T$ allele has been correlated with elevated angiotensinogen. This polymorphism results in a profound vasoconstriction, along with increased BP.,13 The AGTR1 is the primary target for angiotensin II. This protein is a member of the G-protein-coupled receptor family and is expressed in most tissues. The activation of AGTR1 results in water retention, vasoconstriction and vascular smooth muscle cell proliferation, which eventually increases BP. The AGTR1 1166 AC/CC genotype is associated with an increased risk of essential hypertension. ${ }^{14}$

To the best of our knowledge, there have been no studies examining whether genetic polymorphisms modulate BP variations caused by changes in the environmental temperature. In the present study, we examined three RAS genotypes to determine if they affected the association between outdoor temperature and BP. We also sought to

${ }^{1}$ Institute of Environmental Medicine, Seoul National University Medical Research Centre, Seoul, Republic of Korea; ${ }^{2}$ Institute of Medical Research, Seoul National University Bundang Hospital, Seongnam, Republic of Korea; ${ }^{3}$ Department of Biostatistics and Epidemiology, School of Public Health, Seoul National University, Seoul, Republic of Korea; ${ }^{4}$ Institute of Health and Environment, School of Public Health, Seoul National University, Seoul, Republic of Korea; ${ }^{5}$ Department of Medical Engineering, College of Medicine, Seoul National University, Seoul, Republic of Korea; ${ }^{6}$ Bio-MAX Institute, Seoul National University, Seoul, Republic of Korea; ${ }^{7}$ Department of Family Medicine, SamYook Medical Center, Seoul, Republic of Korea and ${ }^{8}$ Department of Family Medicine, Center for Health Promotion, Seoul National University Hospital, Seoul, Republic of Korea Correspondence: Dr M Park, Department of Family Medicine, Center for Health Promotion, Seoul National University Hospital, 103 Daehakro, Jongrogu, Seoul 110-799, Republic of Korea.

E-mail: msp20476@hanmail.net

Received 24 July 2012; revised 23 October 2012; accepted 11 November 2012; published online 7 February 2013 
identify genetically susceptible groups that may require more careful $\mathrm{BP}$ monitoring in response to outdoor temperature change.

\section{METHODS}

\section{Subjects}

Data were collected from 4903 subjects, of mean age 50.5 years (range, 21-86 years). Subjects participating in this study underwent medical screening examinations for health check-up at the Seoul National University Hospital from February 2003 to August 2004. Weather data for the study period, including ambient temperature and relative humidity, were provided by the Korean Meteorological Administration. Daily apparent temperature (AT) was obtained by averaging hourly ATs. Hourly ATs were calculated using hourly temperature, relative humidity and wind speed. As such, they represented wind chill, heat index and hourly temperatures (see Supplementary Appendix A for more detailed information).

All subjects completed structured, self-reporting questionnaires containing information on age, education level, occupation, income, marital status, smoking habit, alcohol consumption, exercise and history of hypertension and diabetes mellitus. Smoking status was divided into three categories: current smoker, former smoker and nonsmoker. Regarding alcohol consumption, the subjects were categorized into two groups: non drinkers and regular drinkers (once a week or more). Exercise was defined as regular exercise (more than $30 \mathrm{~min}$ at least three times a week) or no regular exercise. This study was approved by the Institutional Review Board at the Seoul National University Hospital.

\section{Measurements and definitions}

BP was measured by trained nurses using standard mercury sphygmomanometers. Before measurements, subjects were rested for at least $10 \mathrm{~min}$ in a sitting position. During the $30 \mathrm{~min}$ preceding the measurement, subjects were required to refrain from smoking or consuming caffeine. Two readings (5 min apart) for both SBP and DBP were taken and averaged for the final result.

\section{DNA analysis}

Peripheral leukocytes were isolated from whole-blood samples drawn from the subjects. Genomic DNA was then extracted using a Wizard Genomic DNA purification kit (Promega, Madison, WI, USA), in accordance with the manufacturers' protocol. I/D polymorphisms in intron 16 of the ACE gene were identified as described previously. ${ }^{15}$ AGT M235T and AGTR1 A1166C polymorphisms were analyzed using the TaqMan method and an ABI 7900HT Sequence Detection System (Applied Biosystems, Foster City CA, USA). The TaqMan reaction was carried out using $50 \mathrm{ng}$ of genomic DNA, $2 \times$ TaqMan PCR Master Mix (Applied Biosystems), sense and antisense primers (Bioneer, Daejeon, Korea), and a TaqMan probe for each genotype (Applied Biosystems). Sequences of primers and probes used for genotyping assays are given in Supplementary Appendix B.

\section{Statistical analysis}

Data for SBP and DBP were separated by age group ( $<60$ years $v s$. $\geqslant 60$ years), sex, genetic variants of RAS (ACE (II + ID/DD), AGT (TT/MT + MM), AGTR1 $(A A / A C+C C)$ ), and AT levels (below or above median temperature $\left({ }^{\circ} \mathrm{C}\right)$ ). These data were then analyzed using generalized linear models. In particular, this model was used to determine the effects of RAS genotypes on temperature-dependent BP responses. Nonparametric smoothing regression models were fitted to determine the shape of the association between mean AT $\left({ }^{\circ} \mathrm{C}\right)$ and $\mathrm{BP}$, where the $y$ axis represents the deviation from the mean and the $x$ axis represents AT in ${ }^{\circ} \mathrm{C}$. Stratified analyses were performed on data from each subgroup of genetic polymorphisms. A piecewise linear regression model based on the minimal Akaike information criterion was used to estimate threshold and AT effects both below and above threshold points. ${ }^{16}$ To validate the results, we conducted separate analysis with subjects having visited again for medical screening examinations later. The $\chi^{2}$-test was used for the assessment of Hardy-Weinberg equilibrium in the distribution of genotypes. All procedures were conducted using the $\mathrm{R}$ version 2.12.1 (The Comprehensive R Archive Network, http://cran.r-project.org).

Table 1 Characteristics of study participants $(n=4903)$

\begin{tabular}{lccc}
\hline & Total & Male & Female \\
\hline Participants, N (\%) & $4903(100.0)$ & $2528(51.6)$ & $2375(48.4)$ \\
Age (mean \pm s.d., years) & $50.5(11.2)$ & $50.7(11.4)$ & $50.3(10.9)$ \\
BMI (mean \pm s.d., kg m$\left.^{-2}\right)$ & $24.3(14.0)$ & $26.6(13.3)$ & $21.8(14.2)$ \\
Smoking history, N (\%) & & & \\
$\quad$ No & $2550(54.6)$ & $499(20.5)$ & $2051(91.8)$ \\
Past smoking & $1073(23.0)$ & $995(40.8)$ & $78(3.5)$ \\
Current smoking & $1049(22.5)$ & $945(38.7)$ & $104(4.7)$ \\
& & & \\
Drinking, N (\%) & & & \\
$\quad$ No & $2229(47.3)$ & $574(23.3)$ & $1655(73.5)$ \\
$\quad$ Yes & $2481(52.7)$ & $1885(76.7)$ & $596(26.5)$
\end{tabular}

\section{Exercise, $N(\%)$ \\ No}

Yes

Current use of antihypertensive

medications

Systolic BP $(\mathrm{mm} \mathrm{Hg})$

Diastolic BP ( $\mathrm{mm} \mathrm{Hg})$

Genotypes, $N(\%)$

$D D$

ID

II

$A G T$

$\begin{array}{lccc}\text { MM } & 214(4.4) & 111(4.4) & 103(4.3) \\ M T & 1526(31.1) & 798(31.6) & 728(30.7) \\ T T & 3160(64.5) & 1618(64.0) & 1542(65.0)\end{array}$

\begin{tabular}{lccc} 
AGTR1 & & & \\
$A A$ & $4327(88.3)$ & $2235(88.4)$ & $2092(88.1)$ \\
$A C$ & $561(11.4)$ & $284(11.2)$ & $277(11.7)$ \\
$C C$ & $15(0.3)$ & $9(0.4)$ & $6(0.3)$ \\
\hline
\end{tabular}

Abbreviations: $A C E$, angiotensin-converting enzyme insertion/deletion polymorphism; $A G T$, angiotensinogen M235T polymorphism; AGTR1, angiotensin AT1 receptor A1166C polymorphism; BMI, body mass index; BP, blood pressure.

\section{RESULTS}

The general characteristics of the study subjects are summarized in Table 1. A total of 4903 subjects participated in the study. Of these, $2528(51.6 \%)$ were male. A total of 1180 (24.1\%) subjects were using antihypertensive medications at the time of the visit. Mean SBP and DBP for the subjects were 131.4 and $79.4 \mathrm{~mm} \mathrm{Hg}$, respectively. There were 772 subjects with the $D D$ genotype of ACE (15.8\%), whereas 2332 (47.6\%) had ID and 1792 (36.6\%) displayed II. For AGT, the MM, MT and TT genotypes were present in $214(4.4 \%), 1526(31.1 \%)$ and $3160(64.5 \%)$ subjects, respectively. $A A, A C$ and $C C$ genotypes of AGTR1 were found in 4327 (88.3), 561 $(11.4 \%)$ and $15(0.3 \%)$ of the study participants. The genotypic frequency for these three genes was similar for males and females, with all frequencies showing good fit with the Hardy-Weinberg equilibrium.

In Table 2, mean SBP and DBP are compared by age, sex, RAS gene polymorphisms and AT. Mean (s.d.) SBPs were significantly higher in older subjects ( $<60$ years $v s$. $\geqslant 60$ years, 129.2 (18.3) vs. 139.0 (18.5), $P<0.001$ ) and in males (male vs. female, 134.0 (17.8) vs. 128.7 (19.4)). Similar patterns were observed when mean DBP was 
Table 2 Average values for blood pressure based on age, sex, genotype group,and apparent temperature levels $(N=4903)$

\begin{tabular}{|c|c|c|c|c|c|}
\hline \multirow[b]{2}{*}{ Subgroups } & \multirow[b]{2}{*}{$\mathrm{N}$} & \multicolumn{2}{|c|}{$S B P$} & \multicolumn{2}{|c|}{$D B P$} \\
\hline & & Mean (s.d.) & P-value & Mean (s.d.) & P-value \\
\hline \multicolumn{6}{|l|}{ Age } \\
\hline$<60$ years & 3788 & $129.2(18.3)$ & $<0.0001$ & 78.8 (11.7) & $<0.0001$ \\
\hline$\geqslant 60$ years & 1115 & $139.0(18.5)$ & & $81.8(10.8)$ & \\
\hline \multicolumn{6}{|l|}{ Sex } \\
\hline Male & 2528 & $134.0(17.8)$ & $<0.0001$ & $81.2(11.5)$ & $<0.0001$ \\
\hline Female & 2375 & $128.7(19.4)$ & & 77.5 (11.3) & \\
\hline \multicolumn{6}{|l|}{ AGTR1 } \\
\hline$A A$ & 4327 & $131.4(18.6)$ & 0.4724 & $79.4(11.6)$ & 0.1698 \\
\hline$A C / C C$ & 576 & $132.0(19.9)$ & & 80.1 (11.5) & \\
\hline \multicolumn{6}{|l|}{$A C E$} \\
\hline$D D$ & 772 & $131.4(18.3)$ & 0.9586 & $79.2(11.1)$ & 0.4833 \\
\hline$I D / I I$ & 4124 & $131.4(18.9)$ & & 79.5 (11.6) & \\
\hline \multicolumn{6}{|l|}{$A G T$} \\
\hline$T T$ & 3160 & $131.4(18.3)$ & 0.2284 & $79.2(11.1)$ & 0.3387 \\
\hline$M M / M T$ & 1740 & $131.4(18.9)$ & & 79.5 (11.6) & \\
\hline \multicolumn{6}{|l|}{ Mean AT } \\
\hline$<$ Median & 2447 & $133.0(18.7)$ & $<0.0001$ & $80.4(11.6)$ & $<0.0001$ \\
\hline$\geqslant$ Median & 2456 & $129.8(18.7)$ & & 78.5 (11.5) & \\
\hline
\end{tabular}

Abbreviations: $A C E$, angiotensin-converting enzyme insertion/deletion polymorphism; $A G T$, angiotensinogen M235T polymorphism; AGTR1, angiotensin AT1 receptor A1166C polymorphism; DBP, diastolic blood pressure; SBP, systolic blood pressure.

examined. When temperature was taken into account (below median vs. above median temperature), both SBP and DBP were higher at colder temperatures. Interestingly, genetic polymorphisms of RAS $(A C E(I I+I D / D D)$, AGT $(T T / M T+M M)$ and AGTR1 $(A A / A C+$ $C C)$ ) did not exhibit significant differences in SBP and DBP.

As shown in Figure 1, SBP and DBP decreased with increasing AT. However, to more fully evaluate the relationship between AT $\left({ }^{\circ} \mathrm{C}\right)$ and $\mathrm{BP}$ in terms of genetic status, we performed a nonparametric smoothing regression in each subgroup of genetic polymorphisms (Figure 2). Because we assumed that there was linearity in this relationship, we next analyzed the data using general linear models (Table 3). Temperature was inversely associated with SBP and DBP in the total study population (SBP $\beta=-0.099, P=0.07$; DBP $\beta=-0.1000, P=0.006$ ). These inverse relationships became stronger when we analyzed data from subjects with ACE DD, AGT TT and AGTR1 AA genotypes (SBP $\beta=-0.416, \quad P=0.003$; DBP $\beta=-0.320, P<0.001$ for ACE DD, SBP $\beta=-0.204, P=0.003$; DBP $\beta=-0.154, P<0.001$ for AGT TT, SBP $\beta=-0.133, P=0.024$; DBP $\beta=-0.121, P=0.002$ for AGTR1 AA polymorphism). In contrast, significant relationships were not observed when similar analyses were performed for subjects without these genotypes. Based upon our previous data (Figure 2), we estimated a threshold temperature $\left(21.4^{\circ} \mathrm{C}\right)$ from a piecewise linear regression model at which subjects with the AGTR1 AC/CC genotype would exhibit an upward change in BP. Using this value, we tested for an association between temperature and BP in subjects exposed to temperatures above this threshold. As shown in Table 4, subjects with the AGTR1 $A C / C C$ genotype exhibited a significant rise in SBP and DBP following exposure to elevated temperatures above $21.4^{\circ} \mathrm{C}$ (SBP $\beta=2.208, P=0.038$; DBP $\beta=1.250$, each $P=0.045)$. However, this association was not evident when the temperature range was below $21.4^{\circ} \mathrm{C} \quad(\mathrm{SBP} \quad \beta=-0.044, \quad P=0.798 ; \quad \mathrm{DBP} \quad \beta=-0.020$, $P=0.852)$. Similar results were obtained when we excluded subjects taking hypertensive medications (data not shown). When we evaluated the same relationship in subjects whose data were obtained again at repeated visit $(n=952)$, the estimated effects from the repeated visit data appeared similar to those obtained from the total subjects, although the smaller size of subjects at repeated visits makes the comparison rather difficult (Supplementary Appendix C).

\section{DISCUSSION}

In the present study, we demonstrated that RAS gene polymorphisms modified the associations between outdoor temperature and BP. Whereas BP significantly decreased with rising AT in subjects with ACE DD, AGT TT and AGTR1 AA genotypes, subjects with the AGTR1 $C$ allele showed an elevation of $\mathrm{BP}$ when exposed to higher outdoor temperatures.

The underlying causes of temperature-related variations in BP are not well established. One suggested mechanism for elevated BP in cold weather is increased sympathetic tone. This mechanism is supported by findings of increased plasma and urinary noradrenalin levels following exposure to cold temperature. ${ }^{17}$ In addition, lower BP in hot weather is usually attributed to vasodilation, as well as the loss of water and salt that accompanies sweating. ${ }^{6,18}$ The results of an international collaborative study support this idea, as they show a linear increase in the prevalence of hypertension with latitude across populations of the African diaspora. ${ }^{19}$ Likewise, Barnett et al. ${ }^{6}$ reported a reduction in SBP with increasing outdoor temperature. This was based on data generated by the WHO MONICA project survey, and included 25 populations of mostly European descent from 16 countries.

RAS regulates BP by maintaining vascular tone and water-tosodium balance. ${ }^{7}$ In this study, we chose ACE I/D, AGT M235T and AGTR1 A1166C polymorphisms of RAS because these gene polymorphisms are known to be associated with hypertension. A meta-analysis conducted on a Han Chinese population showed a positive association between essential hypertension and both the TT genotype of AGT M235T polymorphism (odds ratio (OR) 1.54), and the $D D$ genotype of ACE I/D polymorphism (OR 1.61). ${ }^{8}$ These two genetic polymorphisms were found to be associated with hypertension in a recent meta-analysis on Japanese population as well. ${ }^{20}$ The AGTR1 gene 1166 AC/CC genotype has also been linked to hypertension, based on the results of a meta-analysis from a Chinese study (OR 1.48) and from a total of 22 studies of 24 populations (OR 1.13). ${ }^{14,21}$ Although we did not observe significant associations between any of the three genetic polymorphisms and BP, our results suggest that genetic variations result in differential responses of BP to extreme temperatures.

When the slopes of AT on BP were examined for subjects with AGTR1 $C$ allele, a $1{ }^{\circ} \mathrm{C}$ increase above $21.4{ }^{\circ} \mathrm{C}$ resulted in a $2.208 /$ $1.250 \mathrm{~mm} \mathrm{Hg}$ increase in $\mathrm{BP}$, which indicates that heat stress could be life threatening in people with this allele. Interestingly, studies on the AGTR1 polymorphism identified different proportions of genotypes among African, Asian and European populations. For instance, African populations did not exhibit any $A C / C C$ genotype, whereas $10-20 \%$ of Asians and $40-55 \%$ of European populations had this genotype. ${ }^{13,22-26}$ The difference in proportion is likely attributable to differential exposure to certain selection pressures during human 

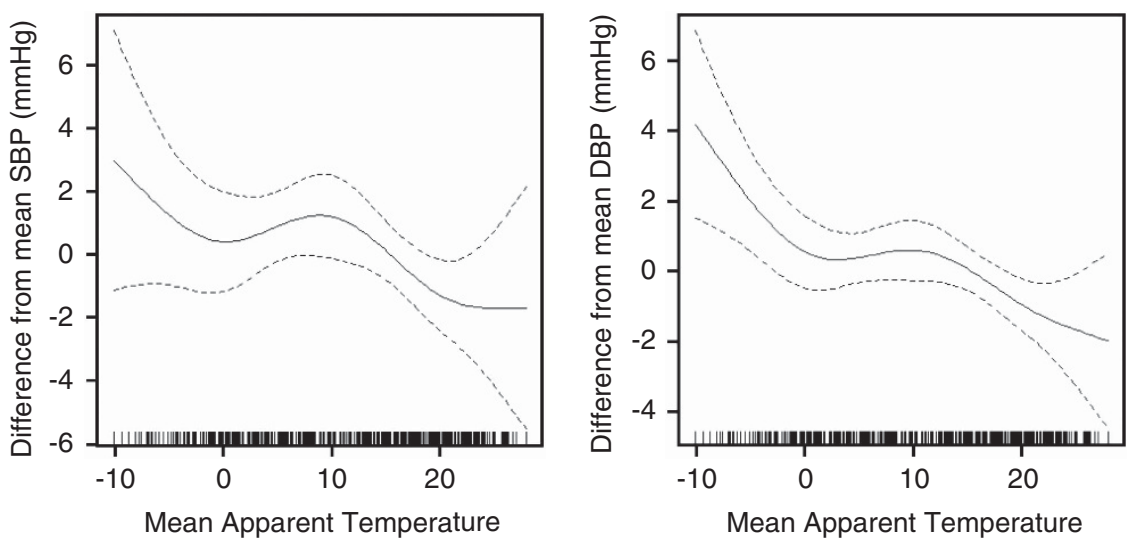

Figure 1 Relationship between mean outdoor apparent temperature $\left({ }^{\circ} \mathrm{C}\right)$ and blood pressure (left plot is for systolic BP and right is for diastolic BP).

a

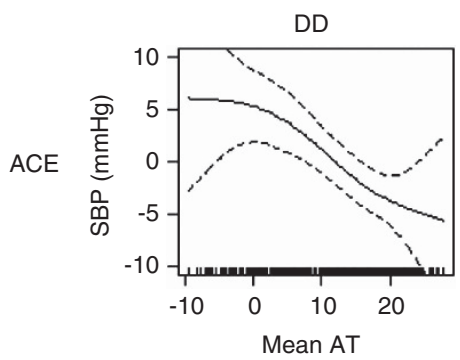

TT

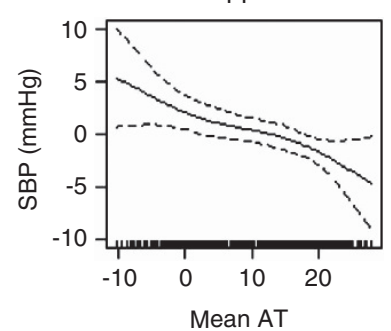

AA

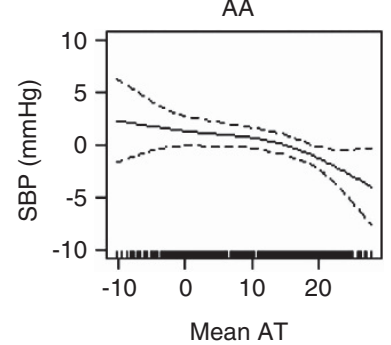

SBP
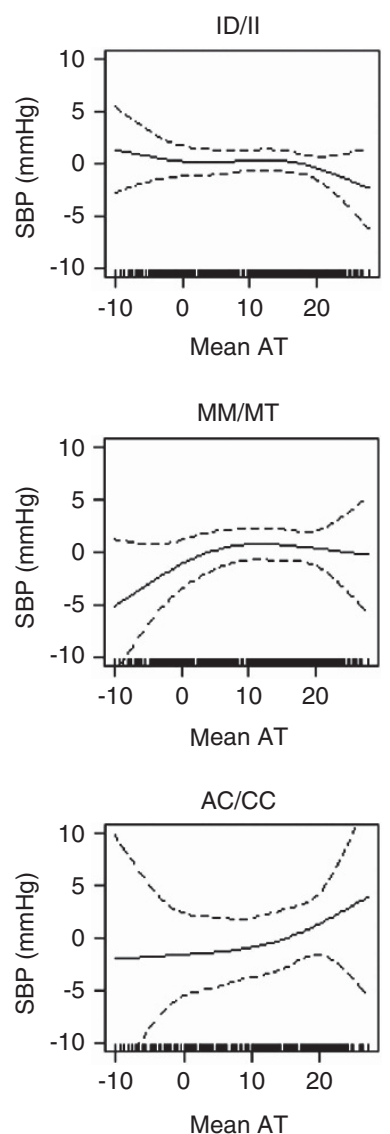

b
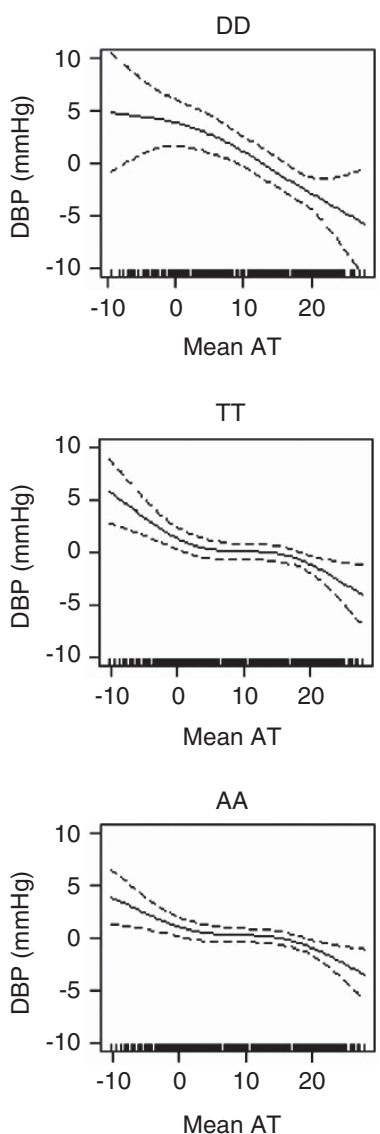

DBP
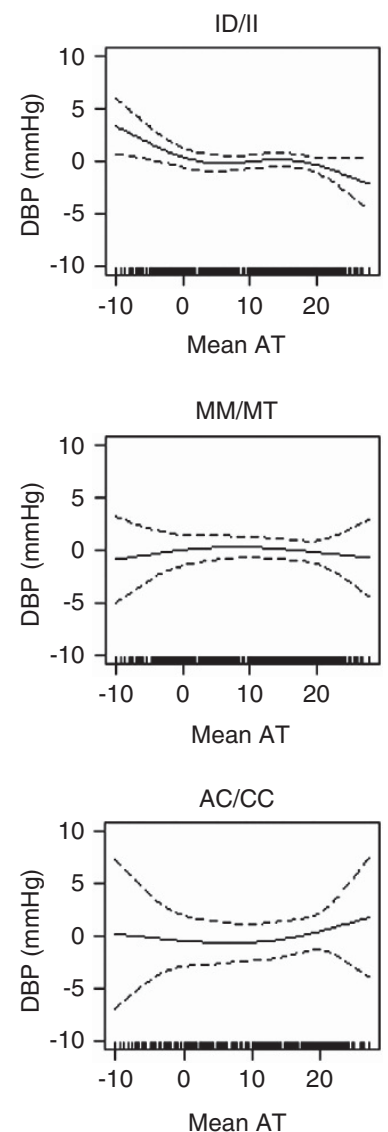

Figure 2 Relationship between daily mean apparent temperature $\left({ }^{\circ} \mathrm{C}\right)$ and blood pressure in subjects with genetic polymorphisms. Graphs for $(\mathbf{a}) \mathrm{SBP}$ and (b) DBP are shown for different polymorphisms of ACE, AGT and AGTR1.

migration. People who were routinely exposed to hot weather would most likely have a smaller proportion of genotypes susceptible to extreme heat. On the other hand, European populations have a larger proportion of AGTR1 AC/CC genotypes, suggesting that they were not typically exposed to high temperature extremes. However, with the prospect of rising temperatures and global warming, European populations could be more at risk for the effects of extreme heat.
In our analysis, we assumed a linear relationship between temperature and BP for all subjects. However, depending on the genotype, we found both underestimates and overestimates of the slope. In particular, linearity assumption was not correct for subjects with the AGTR1 AC/CC genotype. In these subjects, we observed a threshold temperature, which is the value of AT associated with the lowest BP. Therefore, it would be inaccurate to assume linearity 
Table 3 Effect of genetic status on estimated change in blood pressure following a $1-^{\circ} \mathrm{C}$ increase in apparent temperature

\begin{tabular}{|c|c|c|c|c|}
\hline \multirow[b]{2}{*}{ Gene type } & \multicolumn{2}{|c|}{$S B P(m m H g)$} & \multicolumn{2}{|c|}{$D B P(m m ~ H g)$} \\
\hline & $\beta$ (s.e.) & P-value & $\beta$ (s.e.) & P-value \\
\hline Total & $-0.099(0.056)$ & 0.0758 & $-0.100(0.036)$ & 0.0058 \\
\hline \multicolumn{5}{|l|}{$A C E$} \\
\hline$D D$ & $-0.416(0.139)$ & 0.0028 & $-0.320(0.089)$ & 0.0003 \\
\hline$I D / I I$ & $-0.042(0.061)$ & 0.4921 & $-0.061(0.04)$ & 0.1250 \\
\hline \multicolumn{5}{|l|}{$A G T$} \\
\hline$T T$ & $-0.204(0.069)$ & 0.0032 & $-0.154(0.045)$ & 0.0006 \\
\hline$M M / M T$ & $0.093(0.095)$ & 0.3279 & $-0.005(0.061)$ & 0.9327 \\
\hline \multicolumn{5}{|l|}{ AGTR1 } \\
\hline$A A$ & $-0.133(0.059)$ & 0.0244 & $-0.121(0.039)$ & 0.0019 \\
\hline$A C / C C$ & $0.145(0.166)$ & 0.3821 & $0.041(0.102)$ & 0.6856 \\
\hline \multicolumn{5}{|c|}{$\begin{array}{l}\text { Abbreviations: ACE, angiotensin-converting enzyme insertion/deletion polymorphism; AGT, } \\
\text { angiotensinogen M235T polymorphism; AGTRY, angiotensin AT1 receptor A1166C } \\
\text { polymorphism; DBP, diastolic blood pressure; SBP, systolic blood pressure. }\end{array}$} \\
\hline
\end{tabular}

\begin{tabular}{|c|c|c|c|c|c|c|c|}
\hline & \multirow[b]{2}{*}{ Threshold $\left({ }^{\circ} \mathrm{C}\right)$} & \multicolumn{3}{|c|}{ Below threshold } & \multicolumn{3}{|c|}{ Above threshold } \\
\hline & & $\beta$ & s.e. & P-value & $\beta$ & s.e. & P-value \\
\hline $\mathrm{P}(\mathrm{mm} \mathrm{Hg})$ & 21.4 & 0.044 & 0.172 & 0.7982 & 2.208 & 1.063 & 0.0377 \\
\hline $\mathrm{Hg})$ & 21.4 & -0.020 & 0.105 & 0.8520 & 1.250 & 0.623 & 0.0447 \\
\hline
\end{tabular}

Abbreviations: AGTR1, angiotensin AT1 receptor A1166C polymorphism; DBP, diastolic blood pressure; SBP, systolic blood pressure.

between temperature and BP or other health outcomes such as mortality without considering the effects of genotypes.

To the best of our knowledge, this is the first study to identify genetically susceptible subgroup populations, whereby patients exhibit different responses to extreme weather conditions such as high temperatures. We utilized a relatively large number of subjects, to include a sufficient number of patients with minor allele frequencies. However, our study had several limitations. First, a cross-sectional analysis with one measurement may raise concerns, especially when there is a considerable intra-individual variation of BP. However, when we conducted a separate analysis with repeat visit data to test the sensitivity of the results, the effects were similar to the analysis with the first visit data. Second, we only evaluated the short-term effects of outdoor temperature on BP. Therefore, this result is not directly applicable to the long-term effect of weather conditions on BP. Third, all of the study subjects were Koreans living in a temperate climate; thus, this limits the generalization of these findings to people living in regions with other climate conditions.

In conclusion, our analyses of $\mathrm{BP}$ changes suggest that subjects with ACE DD, AGT TT or AGTR1 AA genotypes are susceptible to cold temperature-induced BP increase, whereas subjects with AGTR1 C allele have a high risk of BP elevation when exposed to hot temperatures such as those associated with heat waves.

\section{CONFLICT OF INTEREST}

The authors declare no conflict of interest.

\section{ACKNOWLEDGEMENTS}

Yun-Chul Hong received support from the Susceptible Population Research Program (2008-2010) of the Ministry of Environment. Ho Kim and Youn-Hee Lim were partially supported by the Basic Science Research Program (no. 20100009581) and Global Research Lab (no. K21004000001-10A0500-00710) through the National Research Foundation of Korea (NRF) funded by the Ministry of Education, Science and Technology.

1 Schneider A, Panagiotakos D, Picciotto S, Katsouyanni K, Löwel H, Jacquemin B, Lanki T, Stafoggia M, Bellander T, Koenig W, Peters AAIRGENE Study Group. Air temperature and inflammatory responses in myocardial infarction survivors. Epidemiology 2008; 19: 391-400.

2 Jansen PM, Leineweber MJ, Thien T. The effect of a change in ambient temperature on blood pressure in normotensives. J Hum Hypertens 2001; 15: 113-117.

3 Kunes J, Tremblay J, Bellavance F, Hamet P. Influence of environmental temperature on the blood pressure of hypertensive patients in Montreal. Am J Hypertens 1991; 4 $422-426$.

4 Alpérovitch $A$, Lacombe JM, Hanon $O$, Dartigues JF, Ritchie $K$, Ducimetière $P$, Tzourio C. Relationship between blood pressure and outdoor temperature in a large sample of elderly individuals: the Three-City study. Arch Intern Med 2009; 169: 75-80.

5 Argiles A, Mourad G, Mion C. Seasonal changes in blood pressure in patients with end-stage renal disease treated with hemodialysis. N Engl J Med 1998; 339: 1364-1370.

6 Barnett AG, Sans S, Salomaa V, Kuulasmaa K, Dobson AJ. The effect of temperature on systolic blood pressure. Blood Press Monit 2007; 12: 195-203.

7 Siani A, Russo P, Paolo Cappuccio F, lacone R, Venezia A, Russo O, Barba G, lacoviello $L$, Strazzullo P. Combination of renin-angiotensin system polymorphisms is associated with altered renal sodium handling and hypertension. Hypertension 2004; 43: 598-602.

8 Ji LD, Zhang LN, Shen P, Wang P, Zhang YM, Xing WH, Xu J. Association of angiotensinogen gene M235T and angiotensin-converting enzyme gene I/D polymorphisms with essential hypertension in Han Chinese population: a meta-analysis. J Hypertens 2010; 28: 419-428.

9 Mondry A, Loh M, Liu P, Zhu AL, Nagel M. Polymorphisms of the insertion/deletion ACE and M235T AGT genes and hypertension: surprising new findings and metaanalysis of data. BMC Nephrol 2005; 6: 1 .

10 Rodríguez-Pérez JC, Rodríguez-Esparragón F, Hernández-Perera 0 , Anabitarte $A$, Losada A, Medina A, Hernández E, Fiuza D, Avalos O, Yunis C, Ferrario CM. Association of angiotensinogen M235T and A(-6)G gene polymorphisms with coronary heart disease with independence of essential hypertension: the PROCAGENE study. Prospective Cardiac Gene. J Am Coll Cardiol 2001; 37: 1536-1542.

11 Rudnicki M, Mayer G. Significance of genetic polymorphisms of the renin-angiotensinaldosterone system in cardiovascular and renal disease. Pharmacogenomics 2009; 10 463-476.

12 Sekuri C, Cam FS, Ercan E, Tengiz I, Sagcan A, Eser E, Berdeli A, Akin M. Reninangiotensin system gene polymorphisms and premature coronary heart disease. $J$ Renin Angiotensin Aldosterone Syst 2005; 6: 38-42.

13 Jiang X, Sheng H, Li J, Xun P, Cheng Y, Huang J, Xiao H, Zhan Y. Association between renin-angiotensin system gene polymorphism and essential hypertension: a community-based study. J Hum Hypertens 2009; 23: 176-181.

14 Wang JL, Li X, Hao PP, Feng X, Chen YG, Yun Z. Angiotensin II type 1 receptor gene A1166C polymorphism and essential hypertension in Chinese: a meta-analysis. J Renin Angiotensin Aldosterone Syst 2010; 11: 127-135.

15 Rigat B, Hubert C, Corvol P, Soubrier F. PCR detection of the insertion/deletion polymorphism of the human angiotensin converting enzyme gene (DCP1) (dipeptidyl carboxypeptidase 1). Nucleic Acids Res 1992; 20: 1433.

16 Muggeo VM. Estimating regression models with unknown break-points. Stat Med 2003; 22: 3055-3071.

17 Celi FS, Brychta RJ, Linderman JD, Butler PW, Alberobello AT, Smith S, Courville AB, Lai EW, Costello R, Skarulis MC, Csako G, Remaley A, Pacak K, Chen KY. Minimal changes in environmental temperature result in a significant increase in energy expenditure and changes in the hormonal homeostasis in healthy adults. Eur Endocrinol 2010; 163: 863-872.

18 Young JH, Chang YP, Kim JD, Chretien JP, Klag MJ, Levine MA, Ruff CB, Wang NY Chakravarti A. Differential susceptibility to hypertension is due to selection during the out-of-Africa expansion. PLoS Genet 2005; 1: e82.

19 Cooper R, Rotimi C, Ataman S, McGee D, Osotimehin B, Kadiri S, Muna W, Kingue S, Fraser H, Forrester T, Bennett F, Wilks R. The prevalence of hypertension in seven populations of west African origin. Am J Public Health 1997; 87: 160-168.

20 Takeuchi F, Yamamoto K, Katsuya T, Sugiyama T, Nabika T, Ohnaka K, Yamaguchi S, Takayanagi R, Ogihara T, Kato N. Reevaluation of the association of seven candidate genes with blood pressure and hypertension: a replication study and meta-analysis with a larger sample size. Hypertens Res 2012; 35: 825-831.

21 Niu W, Qi Y. Association of the angiotensin II type I receptor gene +1166A>C polymorphism with hypertension risk: evidence from a meta-analysis of 16474 subjects.. Hypertens Res 2010; 33: 1137-1143.

22 Benetos A, Gautier S, Ricard S, Topouchian J, Asmar R, Poirier O, Larosa E, Guize L, Safar M, Soubrier F, Cambien F. Influence of angiotensin-converting enzyme and 
angiotensin II type 1 receptor gene polymorphisms on aortic stiffness in normotensive and hypertensive patients. Circulation 1996; 94: 698-703.

23 Nishikino M, Matsunaga T, Yasuda K, Adachi T, Moritani T, Tsujimoto G, Tsuda K, Aoki $\mathrm{N}$. Genetic variation in the renin-angiotensin system and autonomic nervous system function in young healthy Japanese subjects. J Clin Endocrinol Metab 2006; 91: 4676-4681.

24 Roberts CB, Rom L, Moodley J, Pegoraro RJ. Hypertension-related gene polymorphisms in pre-eclampsia, eclampsia and gestational hypertension in Black South African women. J Hypertens 2004; 22: 945-948.
25 Sugimoto K, Katsuya T, Ohkubo T, Hozawa A, Yamamoto K, Matsuo A, Rakugi H, Tsuji I, Imai Y, Ogihara T. Association between angiotensin II type 1 receptor gene polymorphism and essential hypertension: the Ohasama Study. Hypertens Res 2004; 27: 551-556.

26 Tiret L, Blanc H, Ruidavets JB, Arveiler D, Luc G, Jeunemaitre X, Tichet J, Mallet C, Poirier O, Plouin PF, Cambien F. Gene polymorphisms of the renin-angiotensin system in relation to hypertension and parental history of myocardial infarction and stroke: the PEGASE study. Projet d'Etude des Genes de l'Hypertension Arterielle Severe a moderee Essentielle. J Hypertens 1998; 16: 37-44.

Supplementary Information accompanies the paper on Hypertension Research website (http://www.nature.com/hr) 